\title{
Linking the World Class Manufacturing System Approach with a Waste Management
}

\author{
Marcela Malindzakova ${ }^{1}$, Dusan Malindzak ${ }^{2}$ \\ ${ }^{1}$ Technical University of Kosice, Institute of Logistics and Transport, Park Komenskeho 14, Kosice, Slovakia \\ ${ }^{2}$ U. S. Steel Kosice, Vstupny areal U. S. Steel Kosice, Slovakia
}

\begin{abstract}
The paper deals with the implementation of the WCM (World Class Manufacturing) model. By implementing the WCM, it is possible to reduce costs in manufacturing operations by removing elements that does not bring added value, or generate losses, waste or even lead to accidents and errors. WCM as a management model includes its own methods and tools that enable the company to achieve profit and a competitive advantage based on the principle of "producing the highest quality products at low prices". The WCM model is based on four concepts to achieve zero waste, zero accidents, zero failures and zero stocks. A prerequisite for the development of the WCM model is the improvement of the company's organizational system in order to achieve a global level of competitiveness.
\end{abstract}

Keywords - World Class Manufacturing, Waste management, Environmental conditions, Environmental protection.

\section{Introduction}

The WCM's implementation process should focus on the following objectives:

- Gradual improvement of quality and efficiency in industrial processes.

- Elimination of waste and losses.

- Improvement in the information field.

DOI: 10.18421/TEM92-43

https://doi.org/10.18421/TEM92-43

Corresponding author Marcela Malindzakova,

Technical University of Kosice, Slovakia.

Email: marcela.malindzakova@tuke.sk

Received: 15 April 2020.

Revised: 12 May 2020.

Accepted: 17 May 2020.

Published: 27 May 2020.

(c) BY-NC-ND (C) 2020 Marcela Malindzakova \& Dusan Malindzak; published by UIKTEN. This work is licensed under the Creative Commons AttributionNonCommercial-NoDerivs 4.0 License.

The article is published with Open Access at www.temjournal.com
- Effective use of time resources.

- Increase in flexibility.

- Increase the level of service for the customer.

The priority objectives of the WCM system aim at maximizing the results of the production process, whilst respecting logistics programs and set quality objectives by ensuring the development of the production process as a result of strengthening competitiveness. The WMC system proposes continuous implementation of standards within the production company, where the target strive to achieve zero stocks, zero failures, maximum efficiency, zero waste, zero losses and zero quality defects. A thorough analysis of possible root causes of any production defects is a solution to any given problem, which however requires the joint effort across the company [1].

Realization of these objectives requires changes in the functioning of the company, methods of operation and management of the production processes.

It can be stated that the definition World-Class Manufacturing (WCM) represents the efforts to achieve the best practices in manufacturing. The definition for WCM comes from Schonberger, who coined the term "World Class Manufacturing", in order to provide an umbrella term for the many techniques and technologies designed to help a company to match its best competitors.

The WCM program has been subsequently implemented by prof. Hajime Yamashina from 2005 at the Fiat Group Automobiles that has adapted WCM approach to match the needs of the company. The implemented model consisted of two main lines of action, called managerial and technical. Both lines further consist of so called pillars, where there are altogether: 10 technical pillars and 10 managerial pillars [2].

\section{The Technical Pillars}

The following areas are specified within the technical pillars: 
- Safety - using tools and regulations, WCM contributes to safety by developing an approach that aims to prevent accidents, the correct use of personal protective equipment, creating safe conditions and avoiding unsafe behaviours, adhering to safety guidelines for the working environment, and many other measures.

- Cost Deployment - the task of a cost analysis is also the introduction of cost-cutting programs through a systematic approach in cooperation with the finance and production department of the organization.

- Focus on improvement - the aim of this pillar is to apply techniques, methods and tools designed to solve difficult problems at a more complex level. Through improvement, the company creates its knowhow. Contribution to improvement is possible through the organization of a job, the Kaizen system or through knowledge gained in previous improvements.

- Professional Maintenance - having professional maintenance in place means reducing the number of failures, downtimes, increasing machine efficiency, and working with maintenance staff. It uses the measures necessary to maintain a suitable environment for workers such as the $5 \mathrm{~S}$ method, the sorting and collection of recyclable waste, the organization of the work area and others.

- Quality Control - this technical part of the WCM is used to determine the process conditions to avoid inconsistencies. It strives to maintain the set conditions to ensure a perfect adaptation of production and product quality at the minimum cost for the company. Quality has to be managed by every employee, because the proper performance of this inspection means delivering products that guarantee maximum customer satisfaction.

- Logistics and Customer Service - the logistics pillar focuses on the synchronization of production and sales in such a way that customers' requirements are fully satisfied. Logistics also aims at minimizing inventory to create a continuous flow and to reduce material handling. It is necessary to reduce stocks to a minimum in order to create a continuous flow. Efforts should also be made to reduce material handling and make proper use of the Kanban and Kaizen systems.

- Early Equipment \& Early Product Management preventive facility care means having reliable facilities that are simple to maintain, acceptable, clean and with low noise levels. It is always important to take into account the knowledge gained from previous experience with equipment.
- People Development - to develop human resources means to use a tool that affects the very essence of the success of the production system. The individual points in the development of human resources are openness and accessibility to gaining new experiences. The company also supports development by carrying out day-to-day activities according to the instructions obtained during training [3], [4].

- Environment \& Energy - according to WCM regulations, the WMC contributes to environmental protection by applying separate collection guidelines, by reducing paper printing, by reducing the generation of pollutants, and wasting of energy resources.

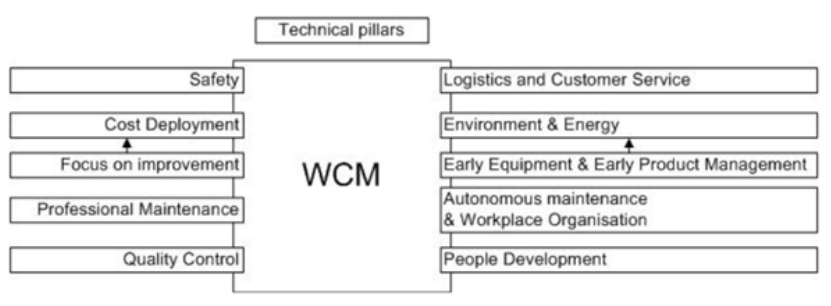

\section{Figure 1. Graphic representation of WCM technical pillars}

The pillar categories are designed to cover the management of the entire organization. They can be applied to any type of production plant. An essential part of each pillar is a seven-step methodology that is implemented to find solutions. The responsibility for each pillar lies with the head of the relevant pillar, which is also responsible for the results of the audits carried out by the WCM Association.

The necessity of the Environment pillar is to continually improve the working environment, meet environmental management requirements in accordance with their requirements and standards. The main activities of the Environment pillar are periodic internal audits aimed at verifying the plant's environmental impacts, identifying risks and prevention, using ISO 14000 series standards and a number of technical improvements, such as site improvement and environmental accident prevention. The aim of the environmental pillar is to reduce the negative impacts on the environment throughout the life cycle of the product from the extracted raw material to its final use.

Part of the Cost Analysis pillar is an analysis and audit that will result in an effective waste reduction plan. An improvement program aimed at reducing waste should be developed. Under the Cost Analysis pillar, it is necessary to identify the costs associated with the waste produced, to identify their place of origin, to evaluate and to select suitable elimination methods [3]. 
The approach of WCM needs to start from a "model area" and then extend to the entire company. WCM is based on a system of audits that give a score that allows getting to the highest level. The highest level is represented by "the world class level" [2].

Another aim of the WCM system is to improve the so called employee's awareness about the problems and issues occurring within the production. The level of awareness of employees can be categorised as follows:

LEVEL 1: Employees do not perceive any issues or question their within production.

LEVEL 2: Employees admit that they have noticed a problem, but they look for excuses claiming no to deal with problem.

LEVEL 3: Employees admit that issues do exist in their company, but they do not know how to solve them.

LEVEL 4: Employees perceive issues; they can identify them and select a solution using an appropriate method.

LEVEL 5: Employees know the kind of issues and appropriate methods to solve them.

They can also get other persons engaged so as to eliminate the problems.

The company within the WCM system should strive to achieve the highest level of averseness of its employees [5].

According to Katarzyna Midor, the following factors are necessary for successful implementation of WCM within a company [5].

- The necessary knowledge of internal processes to identify problems and minimise losses.

- The level of commitment of employees to fully utilise their skills and knowledge to ,tackle the problems".

- The theoretical underpinnings of WMS have to be transformed into practical implementation steps.

The implementation of the WCM model consists of 7 phases, or steps that have to be applied and certified. This is a sequence of steps. To respect environmental requirements and regulations, to develop environmental protection, to continually improve environmental activities as well as to develop specific professional competence, a sevenstep method is required. The result is loss and waste reduction, elimination of contamination sources, improvement of the environment and reduction of potential environmental accidents. The method is divided into three phases:

- Reactive phase (step 0 - 3).

- Preventive phase (step 4 - 5).

- Proactive phase (step 6 - 7).
There are three main approaches to WMC methodology. The first one is called the reactive approach. It involves dealing with the most pressing problems and anomalies with the company, the issues that have to be solved first. The subsequent approach, called preventive one, involves trying to avoid the very occurrence of problems. The last approach called the proactive one involves attempts to identify inconsistencies that might lead to any potential future problems. Considering the WCM approach, a company should strive to operate within the proactive approach across all pillars [1].

\section{Characteristics of the Reactive Phase}

The first part of the reactive phase is the creation of environmental policy and a corporate identity.

Within the reactive phase, environmental aspects and impacts are identified. The following activities cover this reactive phase:

- Development of environmental policy (definition, vision, objectives).

- Specification of preliminary activities (organizational and training plans, procedures, definition of KPIs (Key Performance Indicators) and KAIs (Key Activity Indicators).

- A description of the information flow with regard to the application of environmental legal requirements.

- Assessment of compliance / non-compliance with legal requirements.

- Precise specification of site of environmental aspects / impacts within the plant, assessment of environmental aspects and impacts as well as risk mapping.

The purpose of the second part of the reactive phase is to implement measures with regard to sources of contamination. For the purposes of these measures, it is important to:

- Identify and implement appropriate methods.

- Take action against sources of contamination.

- Evaluate environmental risks.

- Take countermeasures.

The essential activities of this second part of the reactive phase include:

- Intervention and prevention of environmental impact.

- Emergency management.

- Checking the updating for the environmental aspects and impacts assessment.

The aim of the third part of the reactive phase is the preparation of preliminary standards, implementation of standards in other operations within the company, know-how of employees, 
implementation of audited system by senior management, implementation of education system, development of employees' awareness of environmental conditions, risk management methods. The third part of the reactive phase consists of the following activities:

- Characteristics of operational and working procedures.

- Characteristics of support tools for pillar implementation through training, guidance, information and models to address environmental issues

- Addressing similar environmental issues and extending countermeasures to other areas.

- Raising awareness among workers in the field of environmental issues, courses (training) related to environmental management audit.

\section{Characteristics of the Preventive Phase}

The first part of the preventive phase requires identification and calculation of environmental losses. Part of this section is the implementation of measures through specific projects aimed at eliminating waste. Ultimately, it is possible to contribute to improving waste management, reducing potential hazards and improving management of chemicals. The main activities for this step are:

- Environmental cost analysis through loss identification, specification of standards and other conditions, projects aimed at reducing environmental losses.

- Control of chemicals.

- Application of the 5R method.

- Energy saving.

The second part of the preventive phase focuses on the EMS, including the support system, which is the environmental accounting system. The basis of environmental accounting is the calculation of the costs of incorrect environmental procedures, the operating system as well as the reporting system. The primary activities for this section include [6]:

- EMS, certification according to requirements of STN EN ISO 14001:2016.

- Data aggregation system focused on data collection and monitoring.

- Information system for safety and the environment.

Sukarma in his research proposes up to 15 key performance indicators for manufacturing companies to follow if they strive to reach the WCM. Furthermore, he proposes to implement WCM methods in order to measure the company performance and the company's ability to satisfy customers' needs [7].

\section{Characteristics of the Proactive Phase}

The implementation of a system to reduce environmental risks is a necessity for the first part of the proactive phase. To support business activities is to carry out green procurement, finding suppliers whose activities are aimed at eliminating environmental impacts. The essential activities of this part include green procurement, sharing best available technologies and external benchmark. The second part of the proactive phase is based on the use of EMS to create a plant in the form of a model under appropriate environmental conditions.

\section{Method 5R}

The purpose of the $5 R$ method is to analyse the generation and management of waste resulting in the elimination of waste. This method is oriented in two directions:

- Use in conjunction with Environmental Cost Analysis Tool, which ultimately aims to reduce losses.

- Use to improve disposal and waste management objectives while eliminating waste generated during the manufacturing process.

The use of this approach is implemented by all employees, pillar leaders, experts in the interest of eliminating waste. This specific approach focuses on waste projects from three perspectives [8]:

- Reduction or disposal of waste.

- Method of recycling.

- Quantity and production.

The 5R method is based on the following principles (Figure 2):

- Refuse / Reject - comprehensive elimination of the relevant type of waste, efforts to avoid waste generation.

- Reduce / Reject - elimination of waste produced.

- Reuse - efforts to reuse material.

- Recycle - waste management for reuse.

- Recover - efforts to create secondary material (energy recovery from waste).

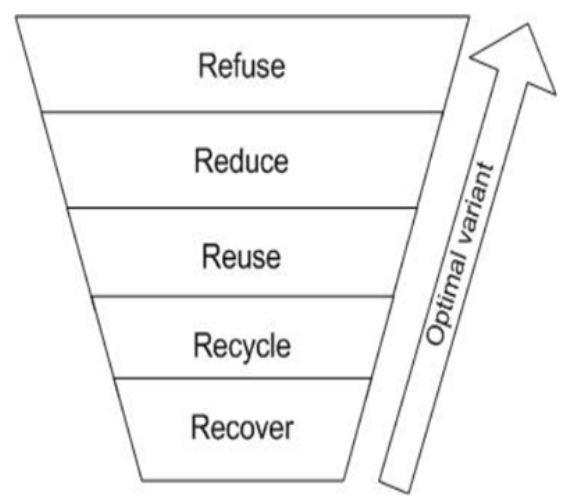

Figure 2. Graphical representation of $5 R$ principles [8] 


\section{Method of Seven Types of Losses}

Seven types of losses can also be used in the WCM model for cost analysis. Individual losses are divided into seven groups:

- Unnecessary consumption - this is insufficient equipment, flow control during non-operational times.

- Surplus Loss - includes material used that exceeds limits.

- Unoptimized loss - represents the use of outdated technology.

- Irreplaceable material - a material that cannot be reused.

- Losses during transport - present e.g. pipe leaks.

- Losses from storage - this includes expiration of materials, excessive ordering of materials.

- Failure to use renewable resources - not to use "green materials".

\section{Waste Management}

The Waste Management is related to ecological production, environmental products and services, reducing environmental impacts, protecting natural resources and developing an overall environmental policy. Rational use of energy, waste reduction, separation and recycling are at the forefront to minimize costs. Emphasis has to be placed on identifying environmental aspects of business activity in order to reduce impacts on the environment. Following the identification of environmental aspects and impacts, legal and other requirements need to be monitored. Sugiarto et.al [9] in article offers exploration study how to implement green business concepts for the company that is trying to achieve green business as a sustainable strategy, whilst at the same time discussing the impacts of green business as well as the driving determinants for green business implementation. The priority of green business is to bring new business opportunities as well as financial savings. The company has to specify the environmental objectives and values that it implements at each level of the company process, while monitoring and measuring any negative deviations that are detected and taking preventive and corrective action. Ultimately, it is also necessary to increase awareness of environmental policies among management and staff of the company.
Regarding the link between the Environmental management and the WCM, the actual connection can be found in the environmental pillar of WCM. There the principles of Waste management can be implemented, where the common factor is to maintain a systematic approach to environmental protection by involving the entire management of the company. As stated by Sandeep there are several factors that determine the effective and easier to implement WCM strategy. Those factors include the commitment of the top management, training of employees, motivation of the management and employees, as well as leadership and planning [10]. Some changes in the organisation structure should be implemented, where a responsible person should be designated for the purposes of facilitating the support and procedures environmental policy.

At present, there is an expected increase in the number of consumers, from business sector and state administration bodies that are interested in meeting the requirements of creation and protection of the environment as well as waste management. Compliance is organized through the demonstration of a systematic approach in the form of application standards that have been developed in a European and in an international context. WCM is a tool that can help solving environmental issues, where the aim is to ensure that measures are taken in the area of sustainable development and waste management.

\section{Conclusion}

The WCM system uses methods that help the company reduce costs while improving quality. To eliminate losses, it is recommended to apply WCM methodology analysis. In this way it is possible to use the 5R method and the method of seven types of losses. Since waste is generated in every activity, the WCM system allows the use of waste reduction methods. In proposals and projects to eliminate losses, even a low percentage of waste volume reduction can be considered a success. In regard to the environment and society, the most appropriate proposal is to reduce waste production, which has a negative impact on the environment and its disposal creates high costs for different types of society.

\section{Acknowledgements}

This article was supported by the Slovak Research and Development Agency under the grants KEGA 017TUKE4/2019 Creating a modular system of synergic cooperation for sustainable development and corporate social responsibility. 


\section{References}

[1]. Cornacchia, L. (2018). A WCM methodology application: the digitalization of the Upstream Check and its organizational impact on the line quality control system (Doctoral dissertation, Politecnico di Torino).

[2]. De Felice, F., Petrillo, A., \& Monfreda, S. (2013). Improving operations performance with world class manufacturing technique: a case in automotive industry. Operations management, 1-30.

[3]. Pałucha, K. (2012). World Class Manufacturing model in production management. Archives of Materials Science and Engineering, 58(2), 227-234.

[4]. Tomek, G., \& Vávrová, V. (2014). Integrované řízení výroby. Od operativního ř́zení výroby $k$ dodavatelskému řetězci. Praha: Grada.

[5]. Midor, K. (2012). World Class Manufacturingcharacteristes and implementation in an automotive enteprise. Zeszyty Naukowe/Akademia Morska w Szczecinie, (32 (104) z. 1), 42-47.
[6]. Zimon, D., Gajewska, T., \& Malindzakova, M. (2018). Implementing the requirements of ISO 9001 and improvement logistics processes in SMES which operate in the textile industry. Autex Research Journal, 18(4), 392-397.

[7]. Sukarma, L., Azmi, H., \& Abdullah, N. L. (2014). The impact of world class manufacturing practices on company performance: a critical review. In Applied Mechanics and Materials (Vol. 564, pp. 727-732). Trans Tech Publications Ltd.

[8]. Pribulova, A., Futas, P., \& Pavucko, S. (2019, July). Recycling of wastes from cast iron castings. In 2019 SGEM conference proceedings. (pp. 763-770).

[9]. Sugiarto, A., Suharti, L., \& Dwiatmadja, Ch. (2019). Building Green Behavior as a Corporate Sustainability Strategy Study on a Green Company in Indonesia. Quality Access to Success, 20(172), 95100.

[10]. Sandeep, R. K. A., \& Panwar, N. (2016). World class manufacturing (WCM) practices: An introspection. International research Journal of Engineering and Technology, 3(5), 2359-2362. 